\title{
¿QUÉ IMAGEN TIENEN DE ROUSSEAU Y VOLTAIRE \\ LAS ACTUALES GENERACIONES ESTUDIANTILES?
}

Claude Lemie*

Nuestra literatura -al menos la que se enseña en los colegios- está llena de contrapuntos: Ronsard y Du Bellay, Corneille y Racine, La Fontaine y Moliére. Pero sin duda la palma del contrapunteo se la llevan la pareja Voltaire y Rousseau. Por cierto ¡Cuántas palabras cruzaron entre sí: al principio dulces y amables y luego agrias y hostiles!

¿Es posible que en ese pequeño panteón que son los manuales escolares esta pareja se haya reconciliado? ¿Cómo se los ve en la escuela hoy? ¿Qué discurso predomina sobre ellos y sobre su relación como autores? Para hacernos a una primera respuesta hemos acudido a un conjunto de textos, el más ecléctico posible, que comprende a todas las obras que son de uso hoy en los colegios, y hemos analizado la selección de fragmentos de sus respectivas obras que suele acompañar a su presentación pedagógica, así como los comentarios con los que se los suele acompañar.

Sabemos que a Plutarco se lo tiene un tanto en el olvido y que su Vida de hombres ilustres hace tiempo dejó de ser la panacea de los latinistas. Sin embargo, al leer a los biógrafos de hoy, nos damos cuenta que su modelo de presentación alternada, antitética, continúa teniendo muchos seguidores.

¿Quién resulta siendo Voltaire en esos manuales? "Hombre de juventud turbulenta" (según Lagarde y Michard, editorial Bordas, en adelante: L y M) "Un libertino" (Chanssaing-Senninger Ed. Hachette, en adelante C-S) "un mundano" ( $L$ y $M$ ), en resumen "un dilettante" (C-S). Al "cortesano decepcionado" (L y M, C-S) le sucede "el patriarca" (C L y M, C-S y también la Histoire de la littérature francaise de Editorial Bordas, en adelante L.F.). En fin, el "rey Voltaire" quien murió "agotado por tanta gloria" (L y M) y "a causa de las emociones de su último triunfo" (C-S).

De su obra se destaca sobre todo que "pocos hombres han recibido juicios tan diversos", se admite que "fue ante todo un polemista" ( $L$ y $M)$. Se reconoce que "Más de una vez acertó" (Le Francais par les textes, Ed. Hatier, en adelante F-T) y a la vez que "fue muy destructivo" ( $L$ y $M$ ). Es suma, se trata de un liberal que "hizo en muchas oportunidades una defensa, teórica es cierto, de la democracia" (L y M).

¡Qué difícil es reconocerlo en esas semblanzasi $O$ más bien: en el perfil del liberal ilustrado que nos trazan, y de hombre honesto que en fin resulta ser, cuyo corazón palpita por un ideal, se pasa por alto sus especulaciones clandestinas sobre los papeles de bolsa de distintos negocios de la época, cómo se silencian sus minuciosas exigencias de gourmet, el tren de vida de gran señor que llevaba en su castillo de Ferney. Se admite

\footnotetext{
* Claude Lemie es especialista en teorías pedagógicas. El presente ensayo apareció en Le Monde: Dossiers-Documents Litteraires, No. 18 de enero de 1998. Traducción de FeRNando Cubides, profesor del Departamento de Sociología e investigador del Centro de Estudios Sociales -CES- de la Universidad Nacional de Colombia. 
claro que "sentía un gran desprecio por la canalla que vivía en la ignorancia y en la superstición" ( $L$ y $M)$ añadiendo, eso sí que "con todo, nunca renunció a instruir a la parte sana del pueblo" (L y M).

¿Citas incompletas y fuera de contexto? En el sistema de trozos escogidos tan propio de nuestros manuales, el discurso del autor del manual se mezcla con el del escritor que está presentando y en demasiadas ocasiones al joven lector le es prácticamente imposible diferenciarlos.

Un ejemplo preciso lo constituyen las ideas políticas de Voltaire. Sabemos que no era propiamente un demócrata. Su ideal siempre fue el de una monarquía ilustrada y parlamentaria a la manera de Inglaterra. Se nos dice, sin embargo, que "confiaba en una elite ilustrada para conducir a la sociedad a la perfección" ( $L$ y $M$ ) y se nos remite enseguida a un nuevo trozo del propio Voltaire, no sin añadir luego que "en conjunto Voltaire lograba discernir una tendencia difusa hacia la civilización". Y sin más se nos envía a un nuevo fragmento de Voltaire, en este caso tomado de su Ensayo sobre las costumbres. Y si en cambio buscáramos un texto en el cual respaldar esa "tendencia difusa hacia la civilización", tal vez sólo podamos encontrar el siguiente: "vemos un amor hacia el orden que anima en secreto al género humano".

Se nota, con ese solo ejemplo entre diez, que la práctica de amalgamar textos transforma el razonamiento volteriano en un juego de escondidas que sólo consigue confundir al lector. ¿En definitiva cuál es la imagen que se quiere dar de Voltaire? La del ideal del liberalismo. Frente a los excesos de un Diderot (demasiado "popular", demasiado estridente, o incluso colérico) y de un Rousseau, el Voltaire que se nos presenta encarna la figura simbólica del francés ingenioso y lleno de espíritu, desfacedor de entuertos (con sus aristas caballerescas a lo d'Artagnan) así como la del escéptico pero respetuoso del orden establecido. Nos encontramos con un Voltaire al gusto decimonónico, cuando el anticlericalismo era de buen tono y combinaba a la perfección con las especulaciones de la burguesía triunfante.

La elección de textos que hacen los antologistas confirma esa percepción. Voltaire resulta ser ante todo el autor de los Cuentos e incluso sólo de uno de ellos el Cándido. Su ideal viene siendo el del hombre de la justa medida, aquél que nos enseña ante todo a "cultivar nuestro jardín"; en el fondo un digno sucesor del fabulista Lafontaine. Si constatamos que el segundo lugar como fuente de esos trozos escogidos lo ocupa El siglo de Luis XIV se precisa el perfil que se nos quiere ofrecer: el filósofo le ha cedido su sitio al hombre de mundo, y proclama, mediante un himno a la gloria del Rey-Sol, la sumisión al orden establecido. Si además tenemos en cuenta que las otras obras de las que se extraen fragmentos son: Zadig, Micromegas y el poema sobre el desastre de Lisboa, se termina el retrato hecho para escolares. Pesimismo y escepticismo, en dosis razonables son los componentes del poder ilustrado, bajo el cual, por lo demás no resulta del todo indecente enriquecerse. En algunos otros textos de consulta se echa mano de algunas de las definiciones del Diccionario Filosófico sobre todo a los artículos "Hombre" y "Tortura" por aquello del toque liberal. Se omiten por completo aquellas otras páginas virulentas del Diccionario como las dedicadas a los artículos "Cristianismo" y "Religión" con lo cual se evidencia la intención de presentarnos una imagen deformada. 


\section{La sexualidad oculta}

¿Acaso se presenta mejor a Rousseau? Veamos. "Una juventud de vagabundeo" (F-T) "aventurero" (C-S) ¿Y su etapa de Les Charmettes? Se pasa púdicamente sobre sus relaciones con Mme de Warens, de la que sólo se afirma que una vez que lo acoge "en adelante la llamará Mamá". No dejan de emitirse juicios como el que sigue: "Incapaz de hacer la corte a las grandes damas, este desheredado se liga a una sirvienta de hotel, Therese Levasseur. Joven y afectuosa pero ignorante y vulgar. Los cinco hijos nacidos de la unión fueron a parar al hospicio. ¿Cómo juzgar esa contradicción con sus teorías pedagógicas? Parece difícil de resolver" ( $L$ y $M)$. No se olvida, sin embargo, que Rousseau "se sentía pueblo" aun cuando frecuentara una "selecta aristocracia". Sus principios resultan determinantes, pues se afirma que de allí beben "Mirabeau, Danton y Robespierre con lo que justifican sus políticas tiránicas en más de una ocasión”. Mientras que nosotros sabemos la importancia capital del pensamiento político de Rousseu, y la influencia decisiva de su sexualidad en su creación literaria, el lector de colegio se queda en ayunas sobre ambos aspectos.

La sexualidad de Rousseau se oculta por completo; presumiblemente (Edipo obliga) por el efecto que pueda producir sobre las mentes adolescentes el episodio completo de Mme. de Warens, primero su madrastra, luego su amante. Se silencia por completo el episodio de Valence, donde gracias a Mme de Larnage el propio Rousseau nos cuenta en sus Confesiones "no morirá sin haber conocido el verdadero placer". Nada se nos dice de sus fiascos con Zulietta, la joven veneciana que quiso iniciarlo, y menos aun de sus affaires con Mme. d'Huodetot, se omite la famosa escena del bosque de Eaubonne (Confesiones, ix ), no se trata precisamente del desplante de un Rousseau "inspirado por el mito del amor puro" ( $L$ y $M$ ) sino simple y llanamente de la impotencia ante una mujer desinhibida y de la que el escritor está profundamente enamorado. Más claro el episodio todavía si sabemos que ella lo ha ido a buscar vestida de hombre y con el látigo en la mano (como por otra parte la muestran los grabados del siglo XIX, que los manuales suelen reproducir fielmente). El hada de la infancia, las maneras autoritarias de las distintas figuras femeninas con las que establece vínculos el ginebrino, desde la primera, la pequeña Goton, estarán siempre presentes en la obra de Rousseau. ¿Cuánto tiempo más será necesario para que los manuales escolares se ocupen de los problemas del inconsciente?

Las Confesiones y las Ensoñaciones de un paseante solitario son las obras de Rousseau citadas con mayor frecuencia. $Y$ siempre los mismos pasajes: el de la noche estrellada, el de la cinta robada, el paseo por el lago, la caída que le provocara el mastín, se va delineando la figura del vagabundo, del mal hombre. Del simple soñador que aspira a la tranquilidad de su casita campestre. $Y$ muy poco o nada se alude al estilista incomparable, al músico, al autor que sabe describir con tanta intensidad sus propias sensaciones.

Vayamos ahora a sus ineludibles obras políticas. Sorpresa: en vez de esa categoría aparece una novela como la Nueva Eloísa. Símbolo del amor puro e imposible y "prerromántico" y .totalmente insípido. Enseguida se nos presenta al Emilio silenciando eso sí su antifeminismo. Del Contrato Social no figura sino la última parte (en invariablemente el mismo pasaje: el del "pacto social"), así como del Discurso sobre la desigualdad nos ofrecen siempre el mismo trozo: "el primero que cercó un terreno etc, etc.". De tal modo que del autor político, inconcluso, deformado, sólo se retendrá en el mejor de los casos la imagen de un misántropo, enemigo de la sociedad y de la propiedad. 
Si se compara esa selección de extractos con las obras del Voltaire y de Rousseu en colección de bolsillo, nos encontramos con que la frecuencia de los trozos corresponde exactamente a la de las ediciones de bolsillo, que los antologistas no se han molestado en consultar las ediciones más completas. De los dos grandes autores del siglo XVIII, nuestros escolares reciben una imagen fragmentaria y deformada, y unos fragmentos tamizados por las necesidades de la industria editorial.

\section{Convenciones}

L y M.: Lagarde et Michard, Bordas.

C-S: Chassing-Seenninger, Hachette

F-T.: Le francais par les textes, 3e, Hatier.

L.F.:Histoire de la littérature francaise, Bordas.

CASU: Castex et Surer, Hacgette. 